\title{
EL IMAGINARIO RELIGIOSO EN LA PEREGRINACIÓN AL SANTUARIO DEL SEÑOR DE HUAMANTANGA
}

Betsali Curi

Universidad Nacional Mayor de San Marcos

\begin{abstract}
RESUMEN
El presente trabajo trata sobre los imaginarios en la peregrinación al Santuario del señor de Huamantanga, sustentados en la tradición oral tradición oral que cuenta cómo llegó hasta Huamantanga el milagroso escultor que trabajó la imagen de Cristo crucificado que se venera en el pueblo. Cada año en el mes de mayo se hace una peregrinación, rememorando el recorrido que se cuenta en la tradición; a lo largo del camino los devotos han establecido una serie de lugares donde se detienen obligatoriamente ya que, según el imaginario popular, serían los mismos lugares que se describen en el relato.
\end{abstract}

\section{PALABRAS CLAVE}

Huamantanga / Imaginarios / Peregrinación / Señor de Huamantanga / Tradición oral.

\begin{abstract}
This paper is about the collective imaginary in the pilgrimage to the Sanctuary of Señor de Huamantanga, this imaginary is supported in the oral tradition about how a miraculous sculptor got on to Huamantanga and how he made the sculpture of Christ that is venerated in the village. The road that devotees carry on every years was inspired in that tradition, and in some parts of the way, there are symbols that the pilgrims consider sacred, because the people believe that are the same places where the sculptor was.
\end{abstract}

\section{KEYWORDS}

Huamantanga / Collective / Imaginary / Pilgrimage / Señor de Huamantanga / Oral tradition 


\section{INTRODUCCIÓN}

En el presente trabajo hemos considerado que para tratar el tema del imaginario social en la peregrinación al santuario del señor de Huamantanga debemos partir por explicar la estructura simbólica en la que se enmarca este ritual. Es decir la institución social donde se genera la peregrinación y su organización simbólica, a partir de ellas podremos conocer los imaginarios compartidos por los peregrinos que acuden cada año al Santuario del Señor de Huamantanga.

Es la iglesia católica, la que durante la época de la evangelización instituye el culto al Señor de Huamantanga que se convierte en patrono del distrito de Huamantanga que forma parte de la provincia de Canta en el departamento de Lima. El culto a este cristo crucificado se remonta hacia fines del siglo XVI e inicios del XVII.

\section{INICIOS DEL CULTO AL SEÑOR DE HUAMANTANGA}

La doctrina de Nuestra señora de la Natividad de Huamantanga era una de las diez que conformaban el corregimiento de Canta. Los religiosos de la Orden de Nuestra Señora de la Merced, fueron los encargados de evangelizar a la población de Huamantanga e iniciaron la construcción de la iglesia. Con fines doctrinales recurrieron a la imagen de Jesús nazareno, tan usada durante el siglo XVI, para la evangelización, al igual que en los casos del Señor de Huamán en Trujillo, el Señor de Burgos en Huánuco, el Señor de los Temblores en Cuzco y el Señor de Locumba en Tacna (Fernández García, 2000, p. 255). Es así que fue el primer doctrinero de Huamantanga, el padre mercedario fray Juan Bautista del Sacramento 1 , quien llevó al pueblo la imagen del cristo crucificado, que se impuso como patrono del pueblo y desde entonces es grandemente venerada (De Olmedo, 1943, p. 65).

Según otros datos, la imagen del Señor de Huamantanga habría sido obra de un escultor contratado por el curaca Apurichagua, quien iba de camino a Lima cuando divisó al artífice desde el sitio actualmente denominado Tres Cruces. El trabajo fue realizado en el pueblo viejo de Auquimarca, encomienda de Juan Pizarro hijo de Martín Pizarro, debido al gran tamaño que tenía la escultura los curacas de Huamantanga intentaron venderla al pueblo de Quipan, pero esto no fue posible debido a que se

1 También conocido como fray Juan Bautista del Santísimo sacramento 
desató una tempestad. Ésta sería la raíz del mito que se ha ido transmitiendo de generación en generación (Villar Córdova, 1980, p. 10).

Una versión conciliadora la da José María Córdova y Urrutia, quien menciona que fue el mercedario fray Juan Bautista del Sacramento quien llevó la imagen al pueblo en tiempos del cacique Apurichagua. (Córdova y Urrutia, 1840, p. 188). El mercedario abría llegado al Perú hacia 1585, no se sabe la fecha exacta en que llega a Huamantanga, pero se sabe que permanece en el virreinato aproximadamente hasta 1600 cuando se marcha a España siguiendo los consejos del arzobispo Santo Toribio de Mogrovejo (Mondragón, 1750).

Entre los siglos XVII y XVIII este culto fue ganando devotos, y llegaron a existir dos cofradías en su honor, una de indios y otra de españoles. Además se encuentran fuentes escritas que señalan el numeroso grupo de gente que acudía desde Lima cada tres de mayo para ver al Señor de Huamantanga y participar en la fiesta que se organizaba en su honor. Según Ricardo Palma, el culto entró en decadencia hacia 1870 debido a que la imagen original se quemó en un incendio, y la nueva imagen no era considerada tan milagrosa (Palma, 1957, p. 227). Si bien esta es una fuente literaria, lo cierto es que no se encuentran documentos sobre las cofradías dedicadas al Señor de Huamantanga después de 1863.

Durante varios años el culto permaneció de una manera local, hasta que en 1958 un grupo de huamantanguinos, que se habían trasladado a Lima, se enteran de que el lienzo que se sacaba en procesión en su pueblo, había sido enviado a Lima para su restauración e iba a ser regresado a Huamantanga en un camión. Entonces el señor Andrés Aguilar, motivado por un sueño, propuso a sus paisanos llevar el lienzo ellos mismos siguiendo el camino contado en la tradición oral. Finalmente siete huamantanguinos salen un primero de mayo de 1958 desde su local comunal en el distrito del Rímac con rumbo a Huamantanga; llegan al pueblo para el día de la fiesta y acuerdan desde entonces realizar una peregrinación anual de Lima a Huamantanga.

\section{LA TRADICIÓN DEL SEÑOR DE HUAMANTANGA}

Contaremos los rasgos generales de la tradición, ya que existen diferentes versiones. Este relato cuenta como dos comuneros del pueblo de Huamantanga iban de camino a Lima buscando un albañil, un escultor y un 
carpintero para trabajar en la iglesia de su pueblo, cuando se encontraron con un viajero que dijo poder realizar esas tareas. Los comuneros le creyeron y decidieron volver al pueblo con el.

En el camino el viajero demostró su carácter divino al realizar una serie de milagros:

1. Hizo salir agua de una roca formando un puquio para que los comuneros pudieran calmar su sed, mientras tanto él fabricaba una cruz de madera que colocó en una pequeña elevación, desde entonces conocida con el nombre de Cruz verde.

2. Se reclinó sobre una roca en la cual los comuneros vieron quedar grabada la huella de su rostro.

3. Hizo reverdecer un árbol seco para que todos pudieran guarecerse del fuerte brillo solar bajo su sombra, este árbol es conocido como el taro que desde entonces, según la tradición, siempre esta lleno de verdes hojas.

4. Fabricó y clavó tres cruces que representaban a él y a dos los comuneros. En este sitio crece el arbusto cruz-casha denominado así porque sus ramas tienen la apariencia de pequeñas cruces.

Al llegar al pueblo de Huamantanga el viajero comenzó a trabajar solo y en una pequeña choza, pidió que los alimentos se le pasaran por la ventana. Un tres de mayo los huamantanguinos se dieron cuenta de que no estaba el caballo con el que había llegado el viajero y no se escuchaba ruido de trabajo, temiendo haber sido engañados derribaron la puerta y se encontraron con la escultura terminada, pero les pareció que les iba a costar demasiado por lo cual decidieron venderla. La venta no se concretó debido a una fuerte tormenta que se repitió cada vez que intentaron mover la imagen de su sitio, tampoco se pudo trasladar a Lima como solicitaron las autoridades de la iglesia católica. Hacia 1870 el santuario se incendió y dicen que el Señor se fue dejando vacía la cruz.

\section{VERSIONESDELATRADICIÓNDELSEÑORDE HUAMANTANGA}

La tradición del Señor de Huamantanga es contada por cronistas, viajeros, literatos e historiadores. Sin embargo se pueden encontrar variaciones en el relato, por ejemplo la parte del recorrido no es contada por José María Córdova y Urrutia (Córdova y Urrutia, 1840: 187-188), Ricardo Palma (Palma, 1956, pp. 225-227) ni José Manuel Valega (Valega, 1939? , p. 445), además estos hablan de dos escultores que acompañaron a los comuneros. Son las ver- 
siones de los huamantanguinos Teodoro Casana (Casana, 1987, pp. 199-204) y Manuel Sánchez Palacios (SANCHEZ PALACIOS, S/F) en las que se menciona un solo viajero y se describe el recorrido que inspira a la peregrinación.

En 1987 tomando como base estas versiones, el pintor huamantanguino Luis Guardamino, realizó una pintura en la cúpula del Santuario del Señor de Huamantanga, esta pintura es actualmente la más conocida por los fieles ya que la ven al llegar al santuario y además cuenta con una leyenda que explica cada uno de los diez cuadros en los que el pintor ha dividido el relato. Cabe mencionar que es en esta última versión en la cual se incluye el elemento de la piedra en la que los fieles ven el rostro de Cristo, ya que esto no es mencionado en ninguna versión anterior.

\section{LA PEREGRINACIÓN AL SANTUARIO DEL SEÑOR DE HUA- MANTANGA}

Existía un lienzo del Señor de Huamantanga que era sacado en procesión todos los años, este lienzo fue llevado a Lima para ser restaurado, entonces el señor Andrés Aguilar huamantanguino que hacía pocos años se había trasladado a Lima sugiere a sus paisanos que el lienzo fuera llevado por ellos mismos, es así que en mayo de 1958 un grupo de siete personas peregrinan caminando desde Lima hasta Huamantanga. El camino que se cuenta en la tradición, era conocido por los primeros fieles, ya que era el antiguo camino de herradura que se usaba desde tiempos virreinales para llegar desde Huamantanga hasta Lima, antes de que se hiciera la carretera hacia Canta. Es por esto que los comuneros de la tradición oral, relatada anteriormente, iban por ese camino.

Cuando los siete huamantanguinos que habían salido desde Lima llegaron al pueblo de Puruchuco, fueron recibidos por otros paisanos que se habían enterado de su viaje e iban a ayudarlos a cargar el lienzo hasta Huamantanga, al llegar al pueblo fundaron la primera hermandad en honor a este cristo, denominada Hermandad de Lima. ${ }^{2}$

Desde 1958 cada año se camina durante dos días partiendo el 30 de abril desde Santa Rosa de Macas hasta llegar a Huamantanga el 2 de mayo por la tarde. Durante el recorrido la primera parada es el Puquio de Socos que actualmente está casi seco, a su alrededor acampa la Hermandad

2 Estos datos nos fueron proporcionados por el mismo señor Andrés Aguilar (84 años) (02/06/2013). 
de Puente piedra. La segunda parada es Cruz verde donde se reúnen y se realiza una misa de bienvenida a todos los peregrinos y se da inicio oficialmente a la peregrinación. Esta misa es presidida por el padre Ronald Gogin $^{3}$, religioso que desde hace unos años se han convertido en una figura importante para los peregrinos, ya que los acompaña cada año.

Retomando el camino la tercera parada es en El rostro, donde muchos se detienen a contemplar la roca buscando ver en ella el rostro del Señor de Huamantanga, finalmente la devoción hace que todos los peregrinos terminen viendo el rostro. Actualmente esta roca se encuentra enmarcada por una especie de nicho y está ennegrecida por el humo de las numerosas velas dejadas por los fieles.

A la hora del almuerzo se llega al Taro, también conocido como Tara es un árbol que crece en la costa y valles interandinos, los peregrinos más antiguos afirman que este árbol nunca se ha secado y siempre ha estado en el mismo sitio. Esto a pesar de que no es muy grueso lo cual no hace creer que sea tan viejo.

Continuando el camino, antes de llegar al pueblo de Puruchuco, se hace otra parada en el lugar denominado Tres cruces, en donde se pueden ver dichas cruces y también se encuentran los arbustos denominados cruz-casha, aquí los peregrinos se detienen a buscar entre sus ramas las que se asemejen a una cruz, para arrancarlas y llevárselas como amuletos. Ya de noche se llega al pueblo de Puruchuco donde se descansa. El dos de mayo por la mañana se inicia el tramo final del camino que llevará a los peregrinos hasta Huamantanga. Desde hace aproximadamente trece años, por iniciativa del Padre Ronald Gogin, en este tramo se realiza un Vía crucis señalado por catorce cruces de cemento, cada una representa una estación en la cual el religioso acompañado de algunos peregrinos se detienen a realizar oraciones y cantos.

Media hora antes de llegar a Huamantanga, los peregrinos se reúnen en una planicie denominada Lancha en la cual se realiza una misa y se ordenan las hermandades según antigüedad. Finalmente entre las cinco y las

3 Director espiritual de las hermandades. Actualmente asignado a la Parroquia La Inmaculada Concepción en Comas. Es magister en Antropología por la Pontificia Universidad Católica del Perú. Es profesor en la Universidad Sede Sapiense y en el colegio Carlos Wise. Tiene un trabajo, no publicado, desarrollado para su curso maestría en Antropología donde tuvo como profesor al padre Manuel María Marzal. El trabajo esta titulado "Devoción y sentimientos en la peregrinación al señor de Huamantanga". 
seis de la tarde los peregrinos hacen su entrada al pueblo de Huamantanga y acuden directo a la iglesia para ver a la imagen de su devoción.

Existe la creencia de que se debe peregrinar de tres a cinco años seguidos para recibir y agradecer un milagro concedido por el Señor de Huamantanga, que es más efectivo en el caso de sanar enfermedades, por lo cual muchos de los peregrinos acuden a pedir por sus familiares enfermos y usan las cruces como amuletos.

Los creyentes y peregrinos que llegan a visitar el Santuario en muchos casos son huamantanguinos que han migrado a Lima, pero conservan la creencia en el Señor de Huamantanga y durante los días de la fiesta agradecen la protección que les brinda y aprovechan la ocasión para visitar a sus amigos y familiares. Además existe entre los peregrinos el compromiso de compartir su devoción llevando cada año a un invitado, lo cual ha motivado el aumento de los fieles del Señor de Huamantanga, y no es poca la gente de otras regiones que por invitación de un amigo o vecino, han terminado uniéndose a una hermandad.

Es así que actualmente los fieles se agrupan en catorce hermandades: la Hermandad del Señor de Huamantanga de Lima, Hermandad del Señor de Huamantanga Puente Piedra, Hermandad del Señor de Huamantanga Santa Rosa de Puente Piedra, Hermandad del Señor de Huamantanga De la Cruz de Lancha, Hermandad del Señor de Huamantanga de Trapiche, Hermandad del Señor de Huamantanga Federico Villarreal (San Felipe), Agrupación de peregrinos de Independencia, Agrupación de peregrinos del Km. 22 Comas, Agrupación de peregrinos de Santa Rosa de Macas, Agrupación de peregrinos de Santa Rosa de Quives, Agrupación de peregrinos de la parroquia Nuestra señora de la Paz, Agrupación de devotos libres, Agrupación de peregrinos de Chocas, y la Agrupación de peregrinos de Yangas. Aparte también tenemos creyentes independientes que no se unen a ninguna agrupación pero acuden cada año a Huamantanga ${ }^{4}$.

La gran mayoría de personas que acuden a la peregrinación vienen de la zona norte de Lima, de distritos como Comas, Independencia, Los Olivos y Puente Piedra, lo cual nos permite darnos una idea de cómo la

4 Como mencionamos antes se debe tener en cuenta que no todos los peregrinos están agrupados en hermandades, algunos prefieren ser independientes ya que alegan no tener tiempo para las reuniones y actividades. En la peregrinación de mayo de este año (2014) se ha sumado una nueva hermandad, denominada hermandad de Carabayllo. 
migración ha sido un factor importante en la expansión de este culto, desde sus mismos fundadores hasta sus descendientes que promueven la adhesión de nuevos fieles cada año.

\section{CONCLUSIONES}

1. El imaginario social es la forma en la que las personas ven su entorno, esta visión se puede manifestar en historias y leyendas. Además motiva determinadas prácticas comunes en la colectividad que se legitima mediante ellas. (Taylor, 2006, p. 38). En la peregrinación al Santuario del Señor de Huamantanga se rememora la llegada del Cristo a dicho pueblo, realizando milagros en determinados lugares; de este modo los peregrinos entienden que por los milagros realizados en ellos, estos lugares, adquirieron un carácter sagrado. Por tanto la tradición del Señor de Huamantanga, desde sus inicios y con los cambios que ha sufrido a lo largo del tiempo hasta llegar a su versión final, retratada en la cúpula de la iglesia, viene a ser un imaginario que sustenta la visión de los fieles en torno al origen de la imagen que se venera en el pueblo y los lugares sagrados del recorrido.

2. La peregrinación es entendida como un recorrido arduo con el fin de llegar a un lugar considerado sagrado según la tradición religiosa a la que pertenecen, las dificultades del camino son parte del proceso por el cual los creyentes se ponen en contacto con la divinidad, pasando de lo profano a lo sagrado (ELIADE, 197, p. 164). La peregrinación al santuario del Señor de Huamantanga es la práctica colectiva que une a las personas que comparten la devoción, que los lleva a caminar durante dos días siguiendo un camino agreste con el fin de llegar a ver al Cristo que veneran.

3. La estructura de esta peregrinación, está basada en la tradición oral antes mencionada, esta define su recorrido y los puntos de parada obligatorios, como el puquio, cruz verde, la roca, el taro y el pueblo de Puruchuco. En el imaginario de los peregrinos estos lugares son los mismos en los que se detuvo el milagroso escultor que trabajó la imagen del Señor de Huamantanga y por tanto son lugares sagrados en los que se pueden poner en contacto con la divinidad, claro que el lugar central es el Santuario que está erigido, según la tradición oral, en el mismo lugar donde trabajó el escultor. Es así que el relato define las reglas del entendimiento común bajo las cuales se lleva a cabo la práctica colectiva de la peregrinación.

4. Las hermandades, que agrupan a los peregrinos devotos del Señor de Huamantanga, constituyen una pequeña comunidad en crecimiento que 
se legitima mediante la práctica de la peregrinación, la cual contribuye a reforzar y mantener viva la devoción. Los peregrinos comparten otras creencias en torno a la peregrinación, como el recoger las cruces naturales del árbol cruz-casha, los algodones que pasan por las yagas del cristo, el agua que hacen bendecir en la misa que se realiza al llegar al pueblo, junto con elementos comerciales que se pueden comprar en la puerta de la iglesia, son llevados por los fieles como reliquias para que les traigan salud y protección. También está la creencia de que se debe peregrinar tres años seguidos si se quiere que el Señor de Huamantanga les conceda algún milagro.

5. Como todo imaginario social, la tradición del Señor de Huamantanga no ha permanecido invariable en el tiempo, ya que como hemos mencionado existen diferentes versiones que han sido unidas para uniformizar el relato y oficializarlo plasmándolo en la cúpula del Santuario que es visitado anualmente por todos los devotos. En este proceso, a parte de incluir elementos como la roca con el rostro de cristo, ha habido una variación en cuanto al autor de la imagen: En las primeras versiones de la tradición son dos y considerados ángeles, y en las versiones posteriores solo es uno y se le identifica con la figura misma de Cristo. Esta característica dinámica de la creencia, también se ve reflejada en el imaginario del pintor que ha retratado la tradición del Señor de Huamantanga en la cúpula de la iglesia. Además este carácter dinámico del imaginario se puede ver en la inclusión de nuevas prácticas mencionadas anteriormente como la del Vía crucis, que se practica desde el año 2000, que parte del imaginario de que fue Cristo en persona quien recorrió ese camino junto a los comuneros huamantanguinos.

\section{REFERENCIAS BIBLIOGRÁFICAS}

CASANA R. Teodoro

1978 Restos arqueológicos de la provincia de Canta y de la provincia de Huaral. Lima: Imprenta Leoncio Prado.

CÓRDOVA Y URRUTIA, José María

1840 Noticias históricas, geográficas y estadísticas de las provincias de Chancay, Cañete, Ica y Yauyos. En: ODRIOZOLA, Manuel, Documentos literarios del Perú. Colectados y arreglados. Lima: Imprenta del Estado, 1877. Tomo XI. 
ELIADE, Mircea

1974 Tratado de historia de las religiones. Madrid: Ediciones Cristiandad:

FERNÁNDEZ GARCÍA, Enrique

2000 Perú cristiano. Primitiva evangelización de Iberoamérica y Filipinas 1492-1600 e historia de la Iglesia en el Perú 1532-1900. Lima: Pontificia Universidad Católica del Perú, Fondo Editorial.

MONDRAGÓN, Diego de

1750 Crónica de la Orden de la Merced en América. En: http:// ec.aciprensa.com/wiki/Cr\%C3\%B3nica_de la_Orden_de la Merced_en_Am $\% \mathrm{C} 3 \%$ A 9 rica: Ap $\% \mathrm{C} 3 \% \mathrm{~B} 3$ strofe teria_del_pasado:_muerte_del_venerable_padre_fray_-̄Miguel_de Orenes, segunda_vez_provincial_de_\% $\overline{\mathrm{C} 3} \% \mathrm{~A} 9 \overline{\mathrm{s}} \mathrm{-}$ a Lima, y_misiones_de los mercedarios_en_\%C3\%A 9 sta_Ciudad de_los_Reyes\#.U8AT0̄pR 5̄Pg8. [Extraído 07-07-14, 8am]

OLMEDO, Manuel de

1784 Memoria de los religiosos de especial virtud que ha florecido en esta provincia de Lima desde su fundación; por el P. Fr. Manuel de Olmedo. Lima, 12 de marzo de 1784. En: BARRIGA, Víctor (1943) Mercedarios ilustres en el Perú. Arequipa. T. I.

PALMA, Ricardo

1956 Tradiciones peruanas. Aguilar: Madrid.

SÁNCHEZ PALACIOS, Manuel

s/f. El señor de Huamantanga. Reseña histórica de la efigie del Señor de Huamantanga. Tradición que yo escuché. [Disponible en: http:// upload.wikimedia.org/wikipedia/commons/8/83/Senor_de_Huamantanga.pdf]

TAYLOR, Charles

2006 Imaginarios sociales modernos. Barcelona: Ediciones Paidós Ibérica.

VALEGA, José Manuel

1939? El Virreinato del Perú. Lima: Editorial Cultura Ecléctica.

VILLAR CÓRDOVA, Pedro Eduardo

1980 El Chaperito. Lima: Universidad Nacional Mayor de San Marcos, Dirección Universitaria de Biblioteca y Publicaciones. 